\title{
ENTRE EL DECORO Y LA LICENCIA. NUEVAS OBRAS ATRIBUIBLES A LUISA ROLDÁN EN ZAFRA (BADAJOZ)
}

\section{BETWEEN DECORUM AND LICENCE: NEW WORKS BY LUISA ROLDÁN IN ZAFRA (BADAJOZ)}

\author{
Alfonso Pleguezuelo Hernández \\ Universidad de Sevilla. España \\ aplegue@us.es
}

\begin{abstract}
El retablo mayor de la Iglesia Colegial de Zafra (Badajoz) es una obra promovida por los Duques de Feria y un importante conjunto arquitectónico con numerosas esculturas bien documentadas de José de Arce y Alonso Martínez. Las últimas incorporadas a la obra en 1680 (dos relieves y dos esculturas exentas) estaban consideradas anónimas si bien documentadas como procedentes de Sevilla. Un análisis estilístico detenido permite atribuirlas a Luisa Roldán.

Palabras clave: Luisa Roldán, La Roldana, escultura, barroco sevillano
\end{abstract}

The altarpiece of the Collegiate Church of Zafra (Badajoz) is a work sponsored by the Dukes of Feria. It is an important architectural complex with a number of well-known sculptures by José de Arce and Alonso Martinez. The latest sculptures added to the work in 1680 (two reliefs and two freestanding sculptures) were considered anonymous but documented as coming from Seville. A careful stylistic analysis can attribute them to Luisa Roldán.

Keywords: Luisa Roldán, La Roldana, sculpture, Seville Baroque

Preveíamos hace pocos años que las obras de Luisa Roldán ejecutadas durante su etapa sevillana como escultora independiente (ca.1670-ca.1686) debían ser más abundantes de lo que entonces se conocía y que, considerando su marcada personalidad como artista, probablemente, se distinguirían en matices respecto de la de sus contemporáneos e incluso de la realizada por su padre y maestro, diferencias que tal vez ayudarían a identificarlas. El paso del tiempo parece estar confirmando aquella sospecha. En efecto, paulatinamente, se ha ido nutriendo su corpus de nuevas obras de este escasamente conocido periodo vital 
de La Roldana. Primero fueron algunos misterios de la Natividad de Jesús ${ }^{1}$; más tarde se han propuesto como obras suyas, esculturas de mayor envergadura que fueron talladas para completar grandes retablos barrocos ${ }^{2}$. Algunas otras posibles esculturas de etapa sevillana de esta artista han sido dadas a conocer muy recientemente ${ }^{3} \mathrm{y}$ en esta ocasión pretendemos proponer a debate de los especialistas un nuevo conjunto de obras que también, como algunas de las antes citadas, fueron hechas para ser integradas en un retablo y que, además, reflejan, en parte, la temática relacionada con sus Nacimientos, razones ambas coincidentes que vinculan esta nueva propuesta con las antes mencionadas.

Se trata del retablo mayor de la Iglesia Colegial de Zafra (Badajoz), una obra bastante bien documentada y estudiada por competentes colegas pero en la que quedaba algún cabo suelto que ahora pretendemos dejar atado. En este retablo creo identificar cuatro posible nuevas obras de Luisa Roldán que hasta el presente estaban consideradas como anónimas, aunque datadas y documentadas como procedentes de un taller sevillano según publicación de Rubio Masa ${ }^{4}$. El conjunto lo forman dos esculturas exentas que representan a los arcángeles San Rafael y San Miguel, de tamaño natural, y dos relieves en que figuran escenas de las Adoraciones de los Pastores y de los Reyes Magos, respectivamente ${ }^{5}$.

Este gran retablo, por suerte conservado aunque necesitado de una buena restauración que merecen tanto la importancia de la obra cuanto la de sus notables autores, fue costeado por los Duques de Feria y tuvo una historia larga y compleja, relativamente bien conocida, en la que se sucedieron varios proyectos y algunos aumentos sucesivos hasta alcanzar la apariencia que hoy ofrece. El proyecto finalmente llevado a cabo fue presentado, según la documentación publicada, por el arquitecto y ensamblador Blas de Escobar aunque algunos especialistas han sugerido, en virtud del temprano uso del orden salomónico (1658),

${ }^{1}$ PLEGUEZUElo HeRnÁndeZ, Alfonso: "Cuatro belenes inéditos de la Roldana", Ars Magazine, 9, 2011, pp. 88-93; DOBADO FERNÁNDEZ, Juan: "Un nacimiento desconocido de la Roldana", Miryam, Revista Mariana Universal, 365, 2011, pp. 196-197.

${ }^{2}$ HERRERA GARCÍA, Francisco y PEREZ DE TENA, Carmen: "Un San José atribuido a la Roldana en el convento de Santa María La Real de Bormujos", Atrio, 17, 2011, pp. 59-68; PLEGUEZUELO HERNÁNDEZ, Alfonso: "Luisa Roldán y el retablo sevillano", Laboratorio de arte, 24, 2012, pp. 275-300.

${ }^{3}$ PLEGUEZUELO HERNÁNDEZ, Alfonso: "Los cuatro Reyes Magos de Luisa Roldán”, Ars Magazine, 30, 2016, pp. 108-118.

${ }^{4}$ RUBIO MASA, Juan: El mecenazgo artístico de la casa ducal de Feria. Mérida, 2001, pp. 190-204. Agradezco a Francisco Herrera sus ayudas en el acceso a la bibliografía manejada en esta varia.

5 Cada uno de los relieves miden 110 x $125 \mathrm{~cm}$. Las imágenes de los arcángeles no se han podido medir por estar en lugar inaccesible, aunque a simple vista parecen de tamaño natural o tal vez algo mayores. 
que en él pudiera haber intervenido José de Arce ${ }^{6}$. La ejecución de su arquitectura estuvo a cargo del citado Escobar, siendo varios los escultores de Sevilla que participaron sucesivamente en la talla de las figuras y los relieves que lo completan. José de Arce fue el primero en colaborar (Cristo crucificado, San Pedro, San Pablo, Santiago, San Andrés y tal vez el relieve de Dios Padre y las esculturas del sagrario); más tarde le sucedió un gran escultor sevillano pendiente de ser mejor estudiado, Alfonso Martínez (dos virtudes, San Agustín y San Luis, obispo) y, finalmente, fallecidos los dos anteriores, creemos que fue Luisa Roldán quien ejecutó las últimas piezas del conjunto cuando en 1680 se toma la decisión de añadir los dos arcángeles que rematan superiormente las entrecalles y los dos relieves que ocupan los tableros del banco, lisos hasta ese momento. Esta última intervención, hecha cuando el retablo ya estaba concluido, la conocemos gracias a un pago que se abona en esa fecha al porteador encargado de trasladar las dos esculturas y los relieves desde Sevilla, donde estaba el obrador de escultura en que se tallaron, hasta Triana para desde allí iniciar su recorrido por la ruta de la plata hasta llegar a Zafra?.

Tanto las esculturas de los arcángeles -difíciles de analizar hoy por la oscuridad, la gran altura a que se hallan situados y las capas de polvo que los cubrencomo los dos relieves del banco - mucho más accesibles y limpios aunque con algunos daños- responden de forma muy evidente al estilo de Luisa Roldán ${ }^{8}$. Ya Rubio Masa, demostrando una notable perspicacia, percibe que el estilo de esta última intervención en nada se parece al de José de Arce y sí, por el contrario, al de Pedro Roldán. No obstante, siendo una observación muy acertada, el rasgo que llama la atención a este autor es precisamente uno de los más peculiares, aunque también desconocidos, de la hija del célebre escultor y una característica, sin embargo, ausente no sólo en la obra de Arce sino también en la del padre de nuestra artista con cuya producción, en efecto, guarda otras semejanzas que justifican el paralelo percibido. Es preciso adelantar en descargo del autor, que estos

${ }^{6}$ Ya lo dejar entender Rubio, 2001: 193 y lo sugiere más abiertamente RECIO MIR, Álvaro, "José de Arce en la catedral de Sevilla y el triunfo del dinamismo barroco en la escultura hispalense", Laboratorio de Arte, 15, 2002, p. 146.

7 "Más tres mil reales que entregó en Sevilla por cuenta de la escultura de los Angeles y quadros que está concertada en quatro mil cien reales". "Más ciento y quarenta reales que pagó en seis partidas: que están en la segunda memoria del porte de unos libros de oro, de esteras y sogas para los ángeles y llevarlos a Triana y porte del retazo que se trajo en el mes de julio con veinte reales de seras, espuertas y costales" (RUBIO MASA, Juan, op. cit., p. 199, nota 241).

${ }^{8}$ Por tratarse este trabajo de una simple varia y no ser conveniente exceder en su extensión, no haré descripciones y análisis formales detallados para justificar esta atribución, dado que no lo considero tan necesario ni, sobre todo, tan interesante como otras cuestiones de índole iconográfica que plantean un aspecto, según considero, más revelador y original de su paternidad. 
matices expresivos que, según nuestro criterio, marcan una distancia entre la labor del padre y de la hija, no han sido analizados hasta el momento y es precisamente esa la razón por la que interesa resaltarlos en esta ocasión. El rasgo en cuestión es un cierto sentido del humor que se trasluce en el tratamiento de los temas y una clara tendencia a introducir en ellos anécdotas a pesar de que ambos relieves abordan la narración de asuntos de gravedad e importancia teológica como son estos dos episodios evangélicos.

La escena de la Adoración de los Pastores responde a un modelo iconográfico convencional con un tono general cercano a las interpretaciones de Murillo y con evidentes paralelos con otras versiones tridimensionales de Luisa Roldán para este mismo asunto (Figura 1) ${ }^{9}$. Aparecen, a la derecha, junto a la Sagrada Familia, tres pastores de tres edades diferentes y en distintas posturas. A la izquierda, en segundo plano, son tres ángeles los que completan el cuadro de personajes. Dos de ellos parecen comentar la escena que contemplan en tanto que el tercero, ajeno a la conversación de éstos, se distrae con el buey que le está causando molestias por su excesiva cercanía y sus inesperadas demostraciones de afecto lo que se percibe en la posición huidiza de la cabeza del ángel y en la expresión contrariada de su rostro (Figura 2).

En el caso de la Adoración de los Reyes Magos, vemos también una escena con los personajes colocados de forma aparentemente ordenada y serena (Figura 3). Detrás de San José se sitúa un soldado, vestido a la romana. La sagrada familia, compuesta por José, María y el Niño, se sitúa a la izquierda, ligeramente elevados los tres personajes sobre un pequeño escalón, respaldados por el pedestal de una columna y en disposición de atender a los Reyes Magos en el momento en que éstos se aprestan a entregar sus regalos.

Melchor, arrodillado, está ofreciendo el suyo al Niño quien, en respuesta, abre los brazos con gesto acogedor; Gaspar aparece en segundo término, con su presente en la mano izquierda y levantando la derecha en ademán declamatorio mientras mira a Baltasar que se acerca también, alzando la copa dorada de su obsequio y apoyando con garbo su otra mano en la cadera mientras pisa deliberadamente el pie de su page, amonestándole de esta forma discreta por estar enredando y riéndose en lugar de guardar la compostura debida en un momento tan protocolario (Figura 4). Por encima de estos, aparece un personaje que mira directamente al espectador en lugar de estar atento a la importante escena que presencia, tal vez para indicar a éste de forma cómplice, que ante él se está produciendo la embarazosa situación descrita.

${ }^{9}$ Es notable el paralelo de la imagen de María de este relieve respecto del que poseían los duques de T'Serclaes y fue destruido en la Guerra Civil española. La dulce expresión del rostro de San José y la notable presencia de los ángeles y sus tipos físicos son rasgos que recuerdan igualmente otras obras de la misma autora. 
No es este el lugar adecuado para realizar un análisis detallado de los inusuales y novedosos niveles de expresividad de las esculturas de Luisa Roldán pero sí quisiera apuntar que, después de analizar muchas de sus obras con cierto detalle, he creído percibir -y estas obras serían un buen testimonio-, que es ella quien por primera vez rompe en el ámbito de la escultura sevillana moderna con las barreras que el decoro había impuesto desde época anterior. Es ella quien se atreve a introducir en escenas de notable contenido doctrinal, aspectos anecdóticos, casi humorísticos, rasgos que otorgan a la narración un desacostumbrado tono doméstico y cercano que poco hubiera complacido a Francisco Pacheco. Ella es quien decide representar a personajes secundarios en actitudes que se desmarcan de las convencionales normas de decorum y quien con tal fin concede a algunos de sus rostros expresiones de alegría que van desde la leve sonrisa hasta la risa más desinhibida, como en este caso muestra el travieso page del rey Baltasar. Ninguna de estas licencias, sin embargo, he apreciado hasta ahora en la adusta expresividad de las obras de su padre Pedro Roldán y mucho menos en la de sus antecesores de la escuela sevillana por más que en ella aumentaran las expresiones de sentimientos, principalmente dolorosos, respecto del serio, apolíneo e inevitablemente inexpresivo lenguaje de Martínez Montañés cuyo arte, en este sentido, podríamos considerar más una tardía expresión del Clasicismo que no una temprana manifestación del Naturalismo y mucho menos del Pleno Barroco. Dejemos, no obstante, para ocasión futura el problema más complejo de explicar las razones por las que en la escultura sevillana se produce este curioso cambio de actitud con la llegada de esta mujer que fue trasgresora de ésta y de tantas otras convenciones.

Fecha de recepción: 30 de septiembre de 2015.

Fecha de aceptación: 20 de noviembre de 2015. 


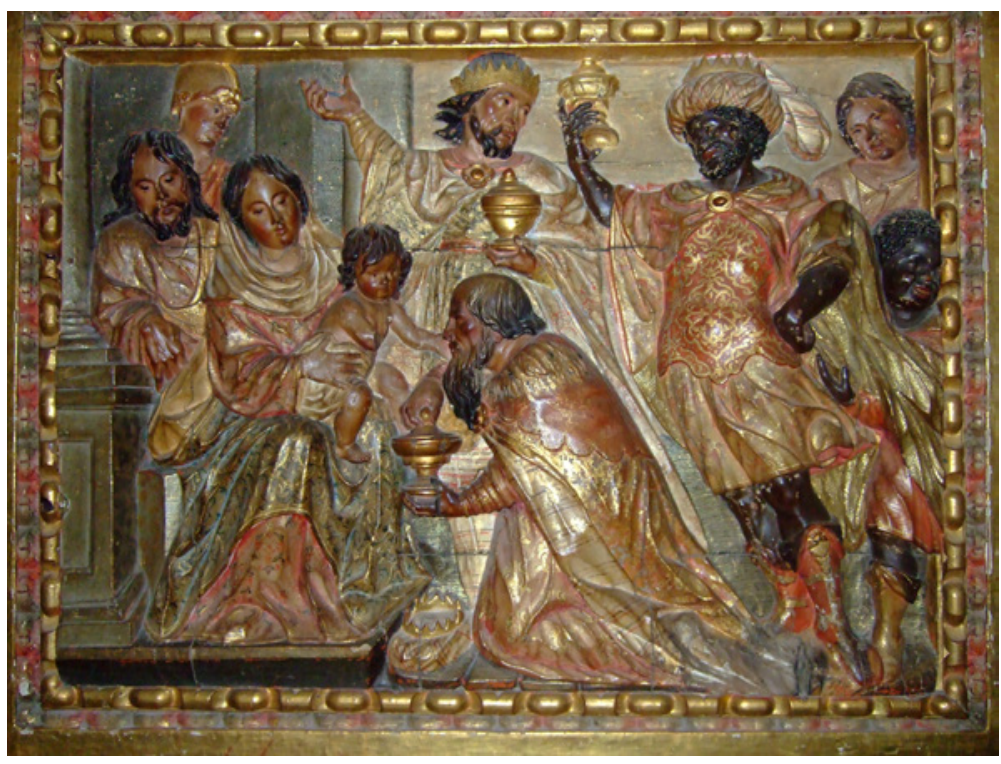

Figura 1. ¿Luisa Roldán?, 1680. Adoración de los Pastores. Retablo mayor de la Iglesia Colegial de Zafra (Badajoz).

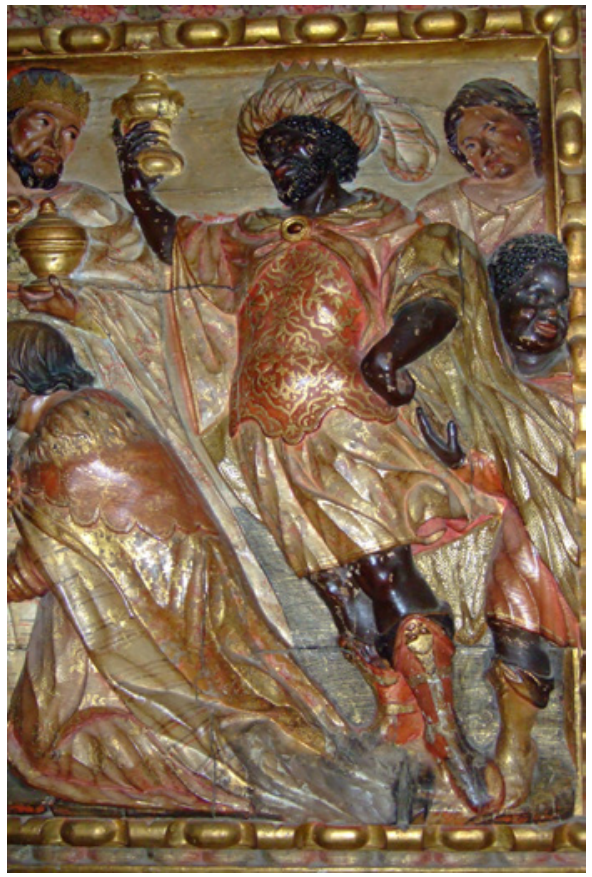

Figura 2. Detalle.

LABORATORIO DE ARTE 28 (2016), pp. 171-177, ISSN 1130-5762

e-ISSN 2253-8305 - DOI http://dx.doi.org/10.12795/LA.2006.i.01.09 


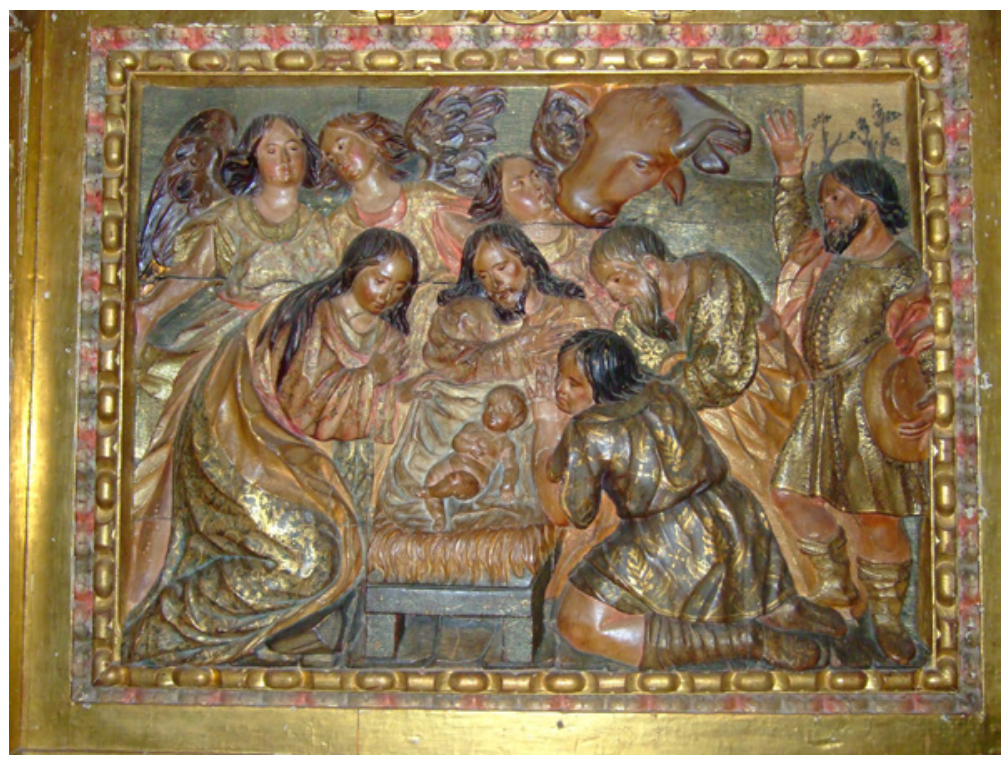

Figura 3. ¿Luisa Roldán?, 1680. Adoración de los Reyes Magos. Retablo mayor de la Iglesia Colegial de Zafra (Badajoz).

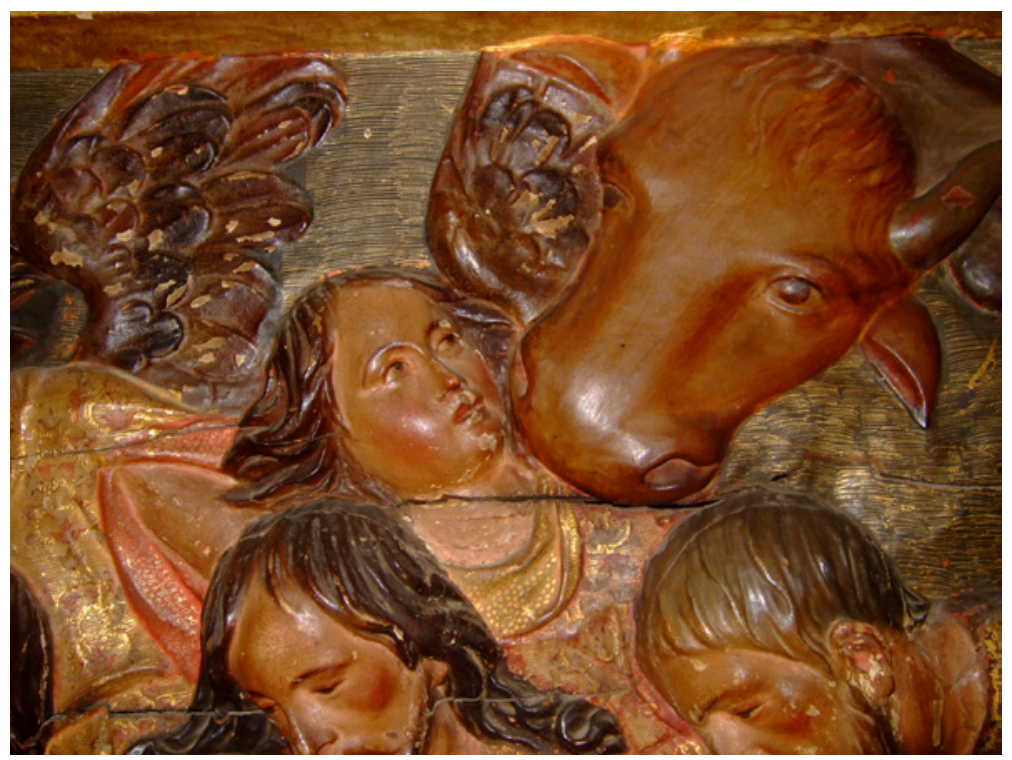

Figura 4. Detalle 